\title{
CHEMICAL SOLUTION PROCESSING OF STRONTIUM BISMUTH TANTALATE
}

\section{FILMS}

\section{C.D.E. LAKEMAN*, T. J. BOYLE**}

*Texas Instruments, Inc., P.O. Box 655012, Mail Stop 921, Dallas TX 75265

(Current Address TPL Inc., 3921 Academy Parkway North, NE, Albuquerque, NM 87109)

**Sandia National Laboratories, Advanced Materials Laboratory, 1001 University Blvd, 9 E:

Albuquerque, NM 87106;

\section{ABSTRACT}

We describe Chemical Solution Deposition (CSD) processes by which Strontium Brith Tantalate (SBT) thin films can be prepared at temperatures as low as $550^{\circ} \mathrm{C}$. In this paper, we will present strategies used to optimize the properties of the films including solution chemistry, film composition, the nature of the substrate (or bottom electrode) used, and the thermal processing cycle. Under suitable conditions, $\sim 1700 \AA$ films can be prepared which have a large switchable polarization $\left(2 \mathrm{P}_{\mathrm{r}}>10 \mu \mathrm{C} / \mathrm{cm}^{2}\right)$, and an operating voltage, defined as the voltage at which $0.80 \times 2 \mathrm{Prmax}$ is switched, $2.0 \mathrm{~V}$. We also describe an all-alkoxide route to SBT films from which SBT can be crystallized at $550^{\circ} \mathrm{C}$.

\section{INTRODUCTION}

The bismuth layered perovskites, such as $\mathrm{SrBi}_{2} \mathrm{Ta}_{2} \mathrm{O}_{9}$ (SBT), have emerged as leading candidates for use as non-volatile memory elements owing to their remarkable polarization fatigue resistance [1-4]. Much research has been directed at tailoring processing conditions to optimize microstructure and properties for use in such devices $[1,2,5]$. Target parameters are: switchable polarization, $2 \mathrm{P}_{\mathrm{r}},>10 \mu \mathrm{C} / \mathrm{cm}^{2}$; coercive voltage, $\mathrm{V}_{\mathrm{c}},<1 \mathrm{~V}$; and operating voltage (defined as the voltage at which $80 \%$ of the switchable polarization can be switched) $<2 \mathrm{~V}$. These parameters indicate the need for thin films $(<2000 \AA)$ for device applications. In addition, to be compatible with standard CMOS circuitry, maximum processing temperatures should not exceed $700^{\circ} \mathrm{C}$.

In order to test the feasibility of SBT for such applications, many researchers have turned to chemical solution deposition (CSD) as a straightforward, rapid method of preparing thin films [3, 6-9]. From the various deposition technologies available, several common features emerge: either complex solution preparation is required to dissolve all components, or high processing temperatures $\left(800^{\circ} \mathrm{C}\right)$ are needed to remove all organic components and form the required layered perovskite phase. Recently, researchers at Sandia National Laboratories (SNL) have reported a simple process that employs readily available starting materials, and from which single phase, ferroelectric films can be formed on $\mathrm{Pt} / \mathrm{SiO}_{2} / \mathrm{Si}$ substrates at temperatures as low as $650^{\circ} \mathrm{C}[6,8]$.

In this paper, we describe experimental strategies to optimize the properties of SBT films prepared by CSD. In particular, details of process developments and optimization will be given, including: 


\section{DISCLAIMER}

This report was prepared as an account of work sponsored by an agency of the United States Government. Neither the United States Government nor any agency thereof, nor any of their employees, make any warranty, express or implied, or assumes any legal liability or responsibility for the accuracy, completeness, or usefulness of any information, apparatus, product, or process disclosed, or represents that its use would not infringe privately owned rights. Reference herein to any specific commercial product, process, or service by trade name, trademark, manufacturer, or otherwise does not necessarily constitute or imply its endorsement, recommendation, or favoring by the United States Government or any agency thereof. The views and opinions of authors expressed herein do not necessarily state or reflect those of the United States Government or any agency thereof. 


\section{DISCLAIMER}

Portions of this document may be illegible in electronic image products. Images are produced from the best available original document. 
- A process for pre-loading the substrate with bismuth which improves the squareness of the ferroelectric P-E hysteresis loops, through better control over stoichiometry in thin films while enabling the processing temperature to be lowered;

- Studies of processing variables, such as film composition, shadow mask top electrode (SMTE) annealing conditions; and

- An ALL ALKOXIDE route to SBT precursors which provides improved solution stability, and enables crystallization of perovskite $\mathrm{SBT}$ at temperatures as low as $550^{\circ} \mathrm{C}$.

\section{EXPERIMENTAL}

A complete description of the processing route developed at Sandia National Laboratories appears elsewhere $[6,8]$. Briefly, bismuth acetate $\left(\mathrm{Bi}(\mathrm{OAc})_{3}\right)$ was mixed and stirred with pyridine (Py). Separately, strontium acetate $\left(\mathrm{Sr}(\mathrm{OAc})_{2}\right)$ and tantalum ethoxide $\left(\mathrm{Ta}(\mathrm{OEt})_{5}\right)$ were mixed and dissolved in glacial acetic acid (HOAc). After stirring for $\sim 10$ minutes, the separate solutions were mixed together, whereupon the $\mathrm{Bi}(\mathrm{OAc})_{3}$ dissolved. All solvents used in the process were dried using standard procedures, and all manipulations were carried out in a glove box under a dry argon atmosphere. Prior to deposition of any solution, $\mathrm{Pt} / \mathrm{SiO}_{2} / \mathrm{Si}$ substrates were cleaned with methanol followed by heating to $400^{\circ} \mathrm{C}$ for 10 minutes in air. After further stirring of the precursor solutions to ensure complete dissolution, films were deposited by spincoating at $3000-7000 \mathrm{rpm}$ for $30 \mathrm{~s}$ followed by drying on a hot-plate at $300^{\circ} \mathrm{C}$ for 5 minutes. After deposition of each layer the films were heated to the desired temperature (typically $700^{\circ} \mathrm{C}$ ) for 30 minutes in flowing oxygen to crystallize the desired perovskite phase. Platinum top electrodes were sputter deposited through a shadow mask, and annealed in oxygen. Ferroelectric properties were measured using a Radiant Technologies RT-66A ferroelectric tester, and surface microstructures examined using a Digital Instruments Nanoscope II atomic force microscope (AFM) in contact mode. Film thickness values were measured using profilometry, and confirmed with scanning electron microscopy (SEM). Standard X-ray diffraction (XRD) was performed on thin films with $\mathrm{Cu} \mathrm{K}_{\alpha}$ radiation using a Siemens automated $\theta-\theta$ powder diffractometer equipped with a diffracted-beam graphite monochromator and a scintillation detector. Parameters for standard scans were a $10-60^{\circ} 2 \theta$ range, $0.05^{\circ}$ step-size and one second count-time. Grazing incidence X-ray diffraction (GIXRD) was also used to examine the phase assemblage of the films. In situ high temperature (HT-GIXRD) analysis was performed by using a film treated at $100^{\circ} \mathrm{C}$ on a hot plate and ramping through various temperatures $\left(8 \mathrm{~min} /{ }^{\circ} \mathrm{C}\right)$ on a hot stage situated in the diffractometer.

\section{RESULTS}

\section{Substrate}

We have described the effects of different bottom electrode annealing conditions on SBT microstructures and properties elsewhere [10]. In essence, annealing the platinum at higher temperatures results in films with higher measured polarization values, though coercive voltage values are similar for the two films. XRD data did not show significant orientation or texture differences and the improved properties were attributed to the larger grain size observed in the films deposited on substrates pre-annealed at higher temperatures.

At the typical processing temperatures used for SBT films $\left(\sim 700-800^{\circ} \mathrm{C}\right)$, significant inter-diffusion between the electrode and film was found to occur (Figure 1). This diffusion caused a change the stoichiometry of the film and led to a deterioration of the properties of the 
ferroelectric film, which could potentially compromised device performance. In addition, at high temperature, volatile heavy metal oxide components, such as $\mathrm{Bi}_{2} \mathrm{O}_{3}$, can be lost via evaporation with similar consequences. Many researchers have compensated for these phenomena by loading the precursor solution composition with an additional 10 to $20 \%$ of the appropriate bismuth component.

In order to overcome these issues, we have developed a novel process to pre-load the platinized $\mathrm{SiO}_{2} / \mathrm{Si}$ wafers with bismuth before deposition of SBT [11]. This was accomplished by spin-coating $(3000 \mathrm{rpm} / 30 \mathrm{~s})$ one coat of a $0.04 \mathrm{M}$ solution of $\mathrm{Bi}(\mathrm{OAc})_{3}$ in a mixture of Py:HOAc ( $1: 2.9$ by weight). After heating on a hot plate at $300^{\circ} \mathrm{C} / 5 \mathrm{~min}$, the wafer was fired at $700^{\circ} \mathrm{C} / 60 \mathrm{~min}$ in air. Residual $\mathrm{Bi}_{2} \mathrm{O}_{3}$ was removed using a basic oxide etch (BOE). Typically an entire wafer was Bi-loaded and etched, then cut into smaller pieces as needed. A comparison of P-E loops measured for films deposited onto loaded and not-loaded substrates is shown in Figure 2.

\section{Composition}

The SBT structure is flexible in that it allows stoichiometry variations for the $\mathrm{Sr}$ and Bi-sites. It has been demonstrated that Sr-deficiency can be compensated by additional Bi which occupies the vacant $\mathrm{Sr}$ sites [12]. This composition variation can affect the measured polarization and coercive field values, as shown in Figure 3 for $\sim 2200 \AA$ SBT films. Values of switchable polarization, $2 \mathrm{P}_{\mathrm{r}}$, reach a maximum for the $10 \% \mathrm{Sr}$-deficient composition (SBT $0.9 / 2.1 / 2.0$ ), and the coercive voltage for $2200 \AA$ films decreases almost monotonically over the entire composition range studied. However, even though the lowest value of $\mathrm{V}_{\mathrm{c}}$ was measured for stoichiometric samples (SBT 1.0/2.0/2.0), the measured 2P $\mathrm{P}_{\mathrm{r}}$ value at this composition was too low for useful device application.

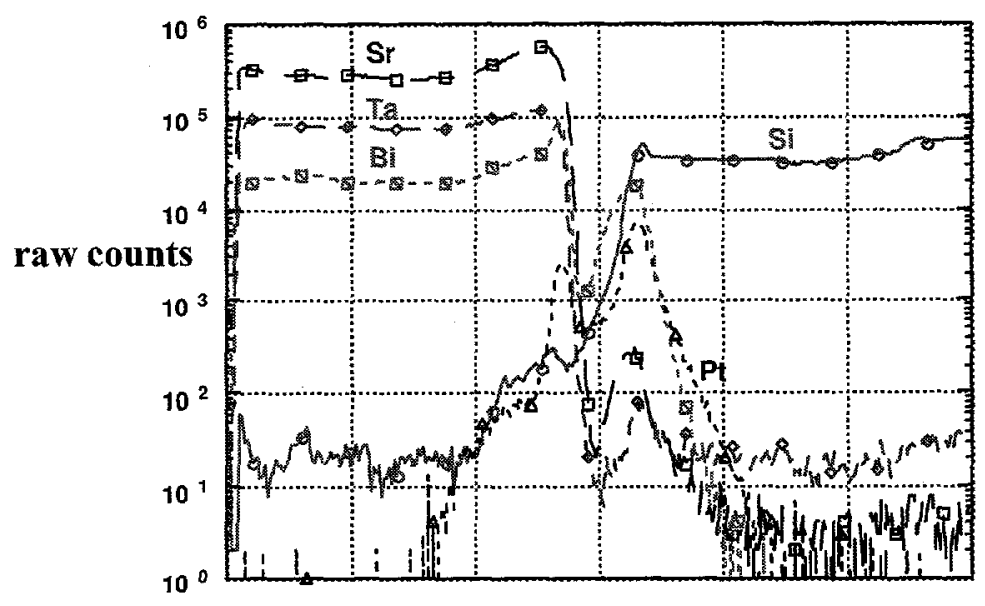

Figure 1 SIMS depth profile of SBT film on $\mathrm{Pt} / \mathrm{SiO}_{2} / \mathrm{Si}$ 


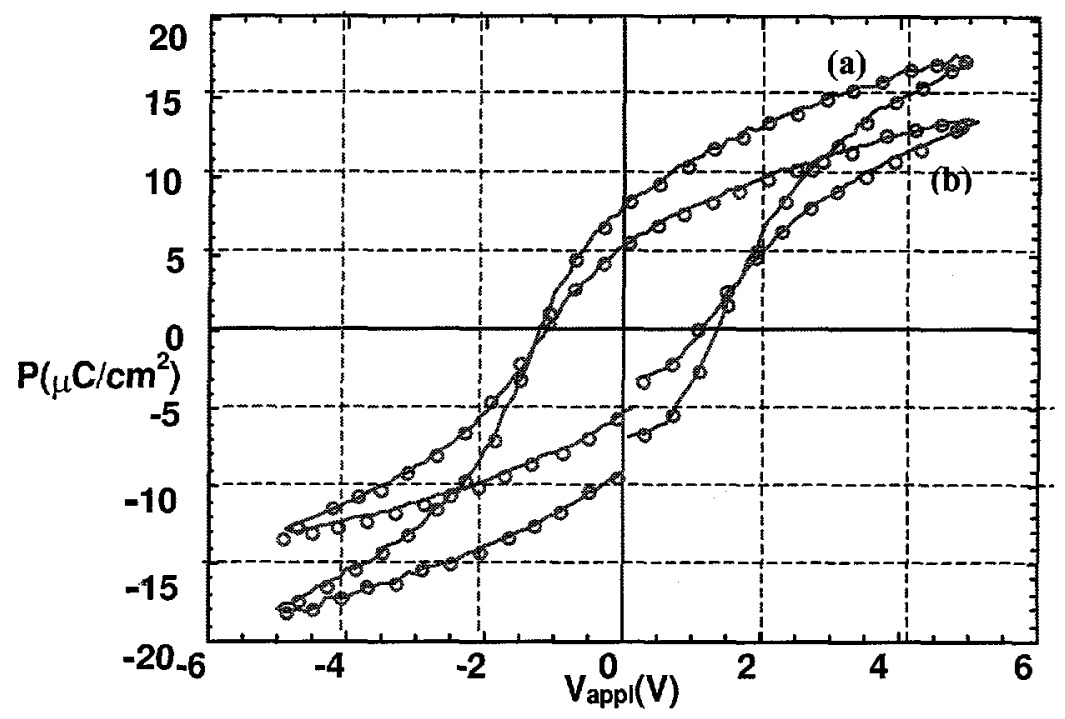

Figure 2 A comparison of P-E loops measured for films deposited onto (a) modified and (b) unmodified $\mathrm{Pt} / \mathrm{SiO}_{2} / \mathrm{Si}$ substrates.

\section{Processing}

Table I lists properties of films prepared with different SMTE annealing conditions, and figure 4 shows representative hysteresis loops. All films were annealed for 30 minutes in oxygen. Annealing at $700^{\circ} \mathrm{C}$ appears to improve the squareness of the loops, and give higher $2 \mathrm{P}_{\mathrm{r}}$ values.

\begin{tabular}{rrrr}
\hline & $550 \mathrm{C}$ & $600 \mathrm{C}$ & $700 \mathrm{C}$ \\
\hline $\operatorname{Ps}\left(\mu \mathrm{C} / \mathrm{cm}^{2}\right)$ & 14.34 & 15.71 & 16.20 \\
$\operatorname{Pr}\left(\mu \mathrm{C} / \mathrm{cm}^{2}\right)$ & 7.41 & 7.98 & 9.67 \\
$\mathrm{Vc}(\mathrm{V})$ & 1.16 & 1.32 & 1.18 \\
$2 \operatorname{Pr}\left(\mu \mathrm{C} / \mathrm{cm}^{2}\right)$ & 12.17 & 13.05 & 18.02 \\
\hline
\end{tabular}

Table I Comparison of SMTE anneal temperature on ferroelectric properties of SBT films.

There are a number of accounts that describe the improvement of ferroelectric properties following a post-SMTE deposition anneal [13-15]. Spierings, et al. suggested that annealing following Pt top electrode deposition on PZT films reorients the polarization direction from parallel to perpendicular to the surface of the films, and attributed a marked improvement in switching behavior to this thermal poling process [13]. On the other hand, Noguchi et al. reported a decrease in the capacitor shorting rate after post-SMTE deposition annealing at $800 \mathrm{C}$ (the same temperature as the crystallization treatment). They believed this was due to recrystallization of the Pt SMTE during the post-deposition annealing treatment, based on SEM analysis of the Pt layer and the Pt/SBT interface [14]. Watanabe and co-workers found that postdeposition heat treatment for Pt SMTE on SBT films resulted in more symmetric polarization reversal behavior (P-E hysteresis loops) and higher breakdown strength $(>300 \mathrm{kV} / \mathrm{cm})[15]$. They reported little difference between annealing at $450^{\circ} \mathrm{C}$ and $800^{\circ} \mathrm{C}$. 

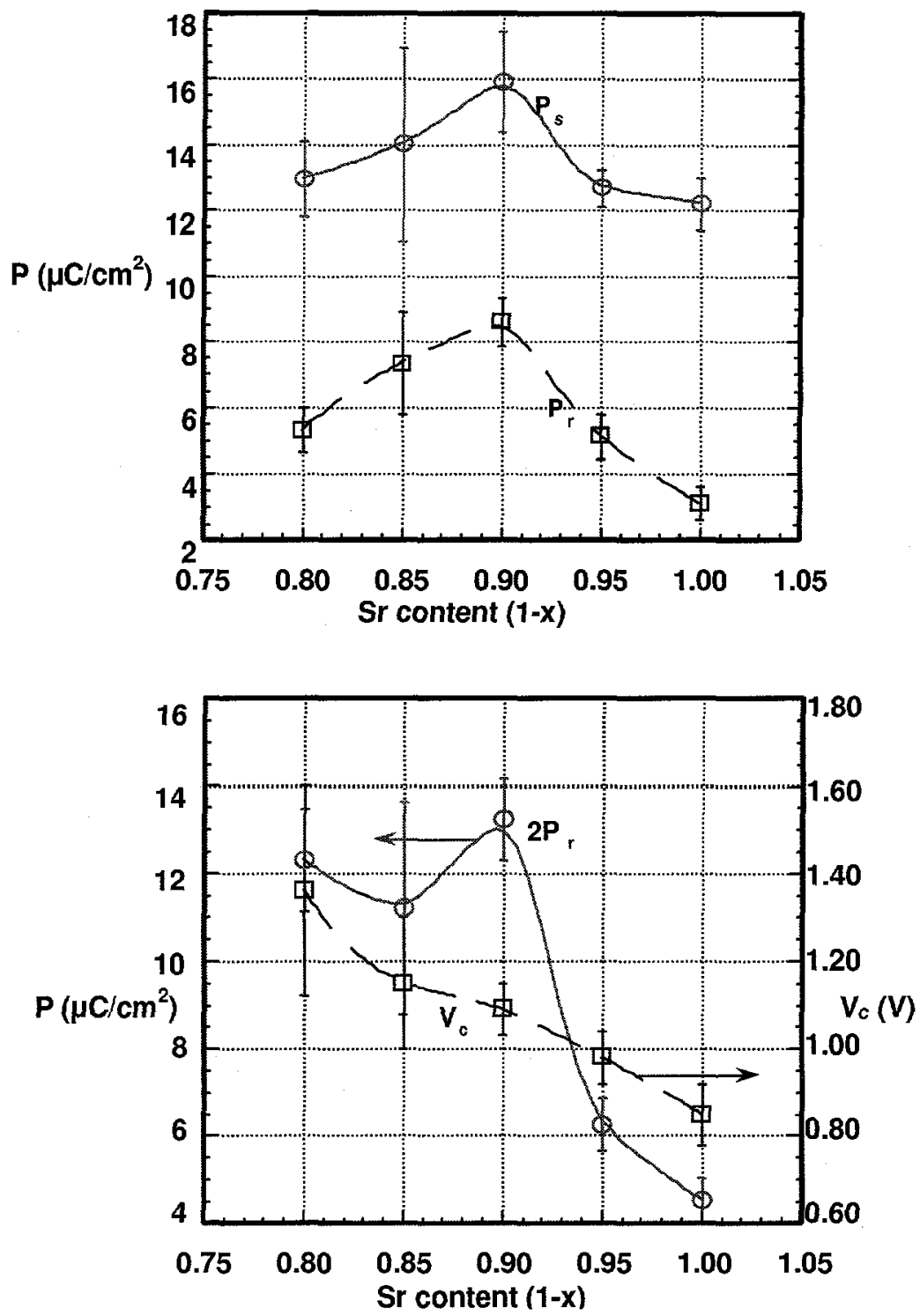

Figure 3 Measured polarization and coercive field values for $\sim 2200 \AA$ SBT films on $\mathrm{Pt} / \mathrm{SiO}_{2} / \mathrm{Si}$ substrate

In situ measurements of stresses in the SBT films through SMTE anneals to $550^{\circ} \mathrm{C}$ and $700^{\circ} \mathrm{C}$ show that the behavior during the heating cycles for both films is quite similar. However, those films heated through $700^{\circ} \mathrm{C}$ undergo further stress relief at temperatures above $550^{\circ} \mathrm{C}$. In other words, annealing to $550^{\circ} \mathrm{C}$ may not allow all stress relief processes to be completed [10].

In order to minimize the operating voltage, films should be as thin as possible. One of the difficulties associated with processing SBT films is the vermicular microstructure that inevitably leads to an increased probability of electrical shorting as film thickness decreases. The optimum $\mathrm{P}-\mathrm{V}$ characteristics obtained for a film on a $\mathrm{Pt} / \mathrm{SiO}_{2} / \mathrm{Si}$ substrate are shown in Figure 5. With a thickness of $\sim 1700 \AA, 2 \mathrm{Pr} \sim 10 \mu \mathrm{C} / \mathrm{cm}^{2}$, the applied voltage at which $0.80 \times 2 \mathrm{Pr}$ max. is switched is $\sim 2.0 \mathrm{~V}$. 


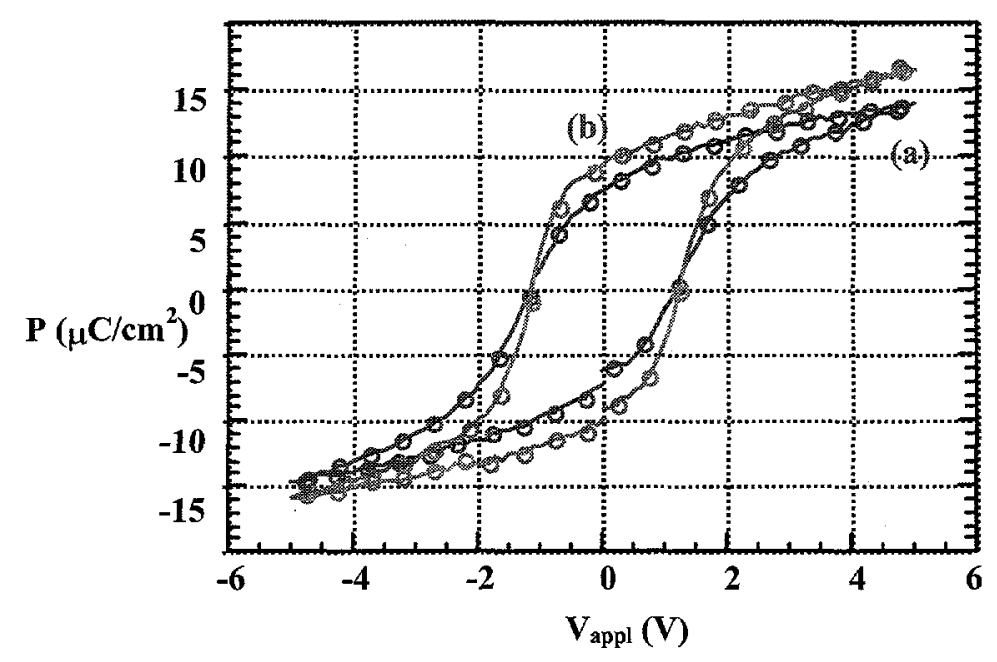

Figure 4 Properties of SBT films prepared under different SMTE annealing conditions:

(a) $550^{\circ} \mathrm{C}$ and (b) $700^{\circ} \mathrm{C}$.

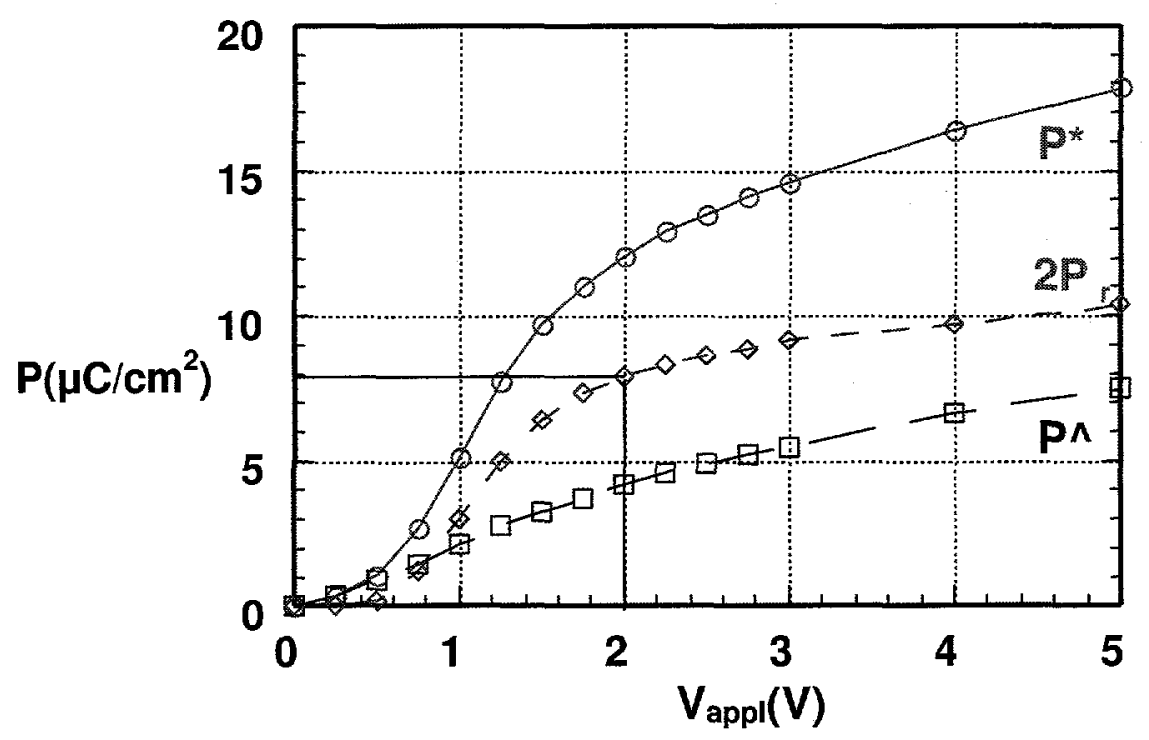

Figure $5 \mathrm{P}-\mathrm{V}$ characteristics for a $1700 \AA$ SBT film on a Bi-modified $\mathrm{Pt} / \mathrm{SiO}_{2} / \mathrm{Si}$ substrate.

\section{All Alkoxide Precursor}

One of the difficulties associated with this precursor system has been the relatively short shelf life of the precursors ( 3 days [6]). While this is offset by the ease of solution preparation, there is a need for solutions which display longer stability, and so, an all alkoxide system has been developed using novel, though readily synthesized, bismuth and strontium alkoxides. 
$\mathrm{Bi}\left(\mathrm{OAr}^{\prime}\right)_{3}$ was prepared from bismuth amide, $\mathrm{Bi}\left(\mathrm{N}\left(\mathrm{SiMe}_{3}\right)_{2}\right)_{3}$, and the alcohol $(\mathrm{HOAr}=2,6$ dimethyl phenol), and $\mathrm{Sr}_{5}(\mathrm{O})(\mathrm{ONp})_{8}(\mathrm{THF})_{5}$ was prepared by direct reaction of strontium metal and excess HONp in THF solvent. To prepare precursor solutions, $\mathrm{Bi}\left(\mathrm{OAr}^{\prime}\right)_{3}$ was slurried in pyridine, forming a pale yellow-green solution. Separately, $\mathrm{Sr}_{5}(\mathrm{O})(\mathrm{ONp})_{8}(\text { solv })_{5}$ was slurried in the same volume of pyridine and stirred. The two solutions were mixed and the resulting green slurry was stirred for $10 \mathrm{~min}$. $\mathrm{Ta}(\mathrm{OEt})_{5}$ dissolved in toluene was added to the $\mathrm{Sr} / \mathrm{Bi}$ mixture and allowed to stir for 30 minutes or until translucent. The solution was then used without further modifications.

Films were deposited by spin-coating onto Bi-modified, Pt-coated $\mathrm{SiO}_{2} / \mathrm{Si}$ substrates at $3000 \mathrm{rpm}$ for 30 seconds. Between each SBT layer, films were inserted directly into a pre-heated furnace at $550^{\circ} \mathrm{C}$ for 20 minutes. After the final layer (typical film had 3 layers), the film was fired at the desired temperature for a predetermined amount of time.

HT-GIXRD experiments indicated that the perovskite phase formed as low as $600^{\circ} \mathrm{C}$ (Figure 6). Based on these data longer processing times at lower temperatures were also examined using in-situ HT-GIXRD at $575^{\circ} \mathrm{C}$. After $\sim 3$ hours the perovskite phase was observed. Lower temperatures over the same time period only produced amorphous films. Using conventional furnace firing, it was determined that the perovskite phase was formed after 24 hours at $550^{\circ} \mathrm{C}$ (Figure 7).

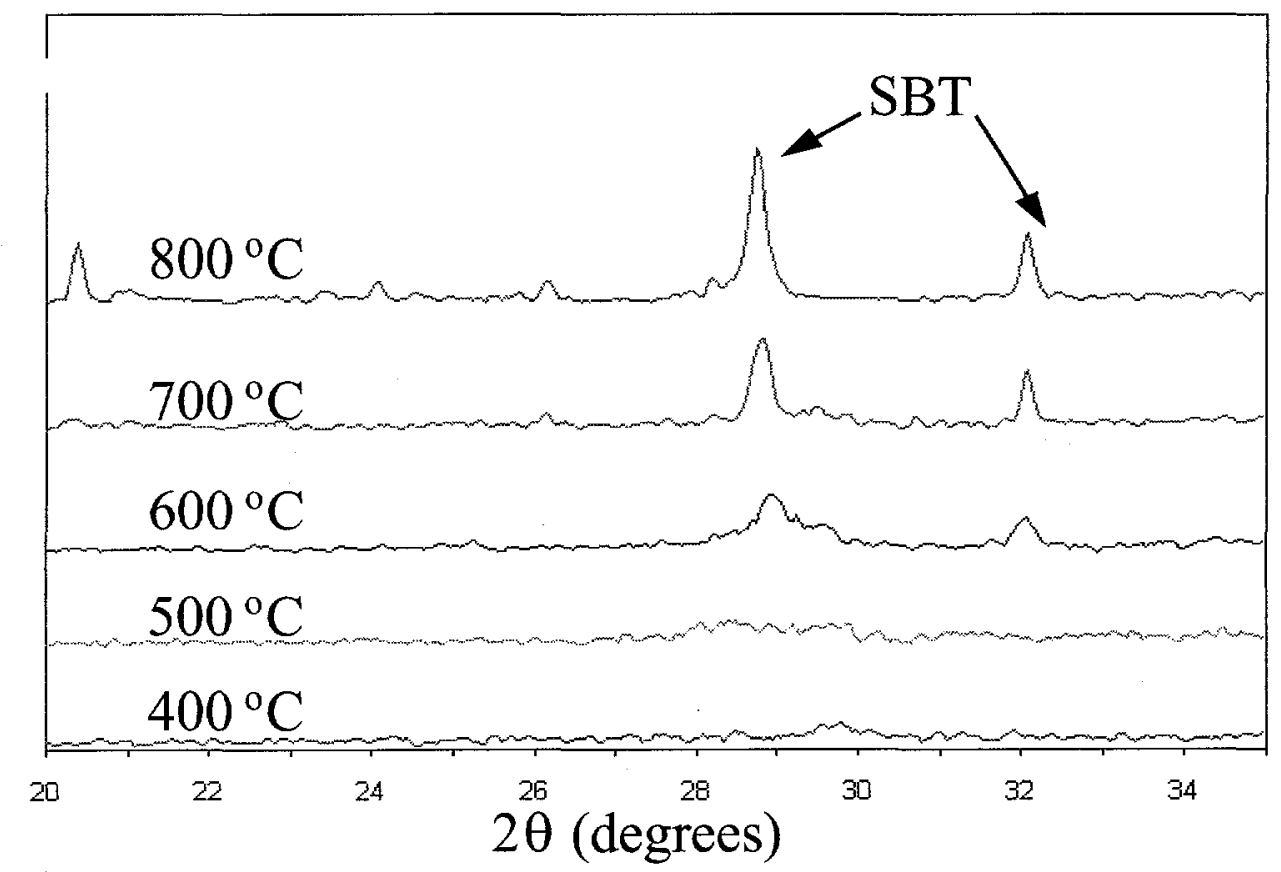

Figure $6 \mathrm{HT}$-GIXRD of all-alkoxide SBT films on Bi-modified $\mathrm{Pt} / \mathrm{SiO}_{2} / \mathrm{Si}$ substrate 


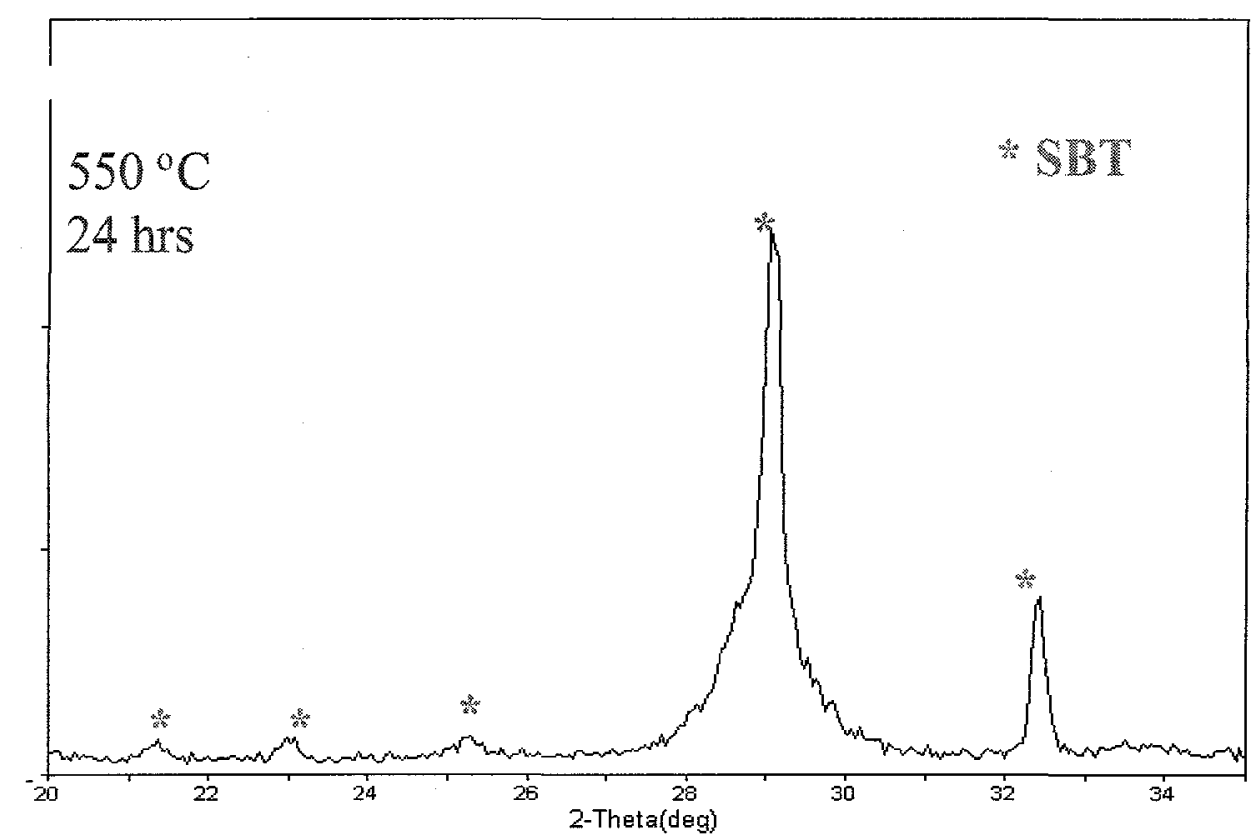

Figure 7 GIXRD of SBT film on Bi-modified $\mathrm{Pt} / \mathrm{SiO}_{2} / \mathrm{Si}$. Note perovskite formation at $550^{\circ} \mathrm{C}$.

\section{SUMMARY}

We have prepared (SBT) films using a chemical solution deposition. Substrate preparation and microstructure, film composition and control over post-SMTE thermal processing have been optimized to tailor film properties to meet parameters suitable for integration. Pre-loading $\mathrm{Pt}$ substrates with Bi before deposition of the SBT films helps to improve control over film stoichiometry, and can lead to improved properties. Precursors to enable an all-alkoxide process have been developed, from which perovskite films have been crystallized at temperatures as low as $550^{\circ} \mathrm{C}$.

\section{ACKNOWLEDGEMENTS}

This work was supported by Texas Instruments, Inc. and the United States Department of Energy under contract DE-AC04-94AL85000. Sandia is a multi-program laboratory operated by Sandia Corporation, a Lockheed Martin Company, for the United States Department of Energy. We would like to acknowledge the assistance of B.A. Hernandez, and C.D. Buchheit of Sandia National Laboratories, and Drs. S. Summerfelt, T. Moise, and S. Yamanaka of Texas Instruments.

\section{REFERENCES}

1. See for example, Ferroelectric Thin Films IV and V, Mater. Res. Soc. Symp. Proc., 361 and 433, (1995, and 1996).

2. See also, Proc. IX ISIF, Santa Fe, NM, March 3 - 5, 1997, Eds. D.B. Dimos, and B.A. Tuttle, in Integrated Ferroelectrics, 17, 18, (1997). 
3. R.E. Jones, P. Zurcher, P. Chu, D.J. Taylor, Y.T. Lii, B. Jiang, P.D. Maniar, and S.J. Gillespie, Microelectronic Engineering, 29, 3, (1995).

4. H.N. Al-Shareef, D. Dimos, T.J. Boyle, W.L. Warren, and B.A. Tuttle, Appl. Phys. Lett., 68, 690, (1996).

5. T. Noguchi, T. Hase, and Y. Miyasaka, Jpn. J. Appl. Phys., 35, 4900, (1996).

6. T.J. Boyle, C.D. Buchheit, M.A. Rodriguez, H.N. Al-Shareef, B.A. Hernandez, B. Scott, and J.W. Ziller, J. Mater. Res., 11, 2274, (1996).

7. K. Amanuma, T. Hase, and Y. Miyasaka, in Ferroelectric Thin Films IV, Mater. Res. Soc. Symp. Proc., 361, 21, (1995).

8. T.J. Boyle US Patent 5683 614, (1997).

9. I. Koiwa, K. Tani, J. Mita, T. Iwabuchi, Jpn. J. Appl. Phys, 37, 192, (1998).

10. C.D.E. Lakeman, T.J. Boyle, J.A. Ruffner, J. of Sol-Gel Sci., In Press, (1998).

11. A patent application by C.D.E. Lakeman and T.J. Boyle has been filed by Texas Instruments on this process (1998).

12. T. Noguchi, T. Hase, and Y. Miyasaka, Integrated Ferroelectrics, 17, 57, (1997).

13. G.A.C.M. Spierings, G.J.M. Dormans, W.G.J. Moors, M.J.E. Ulenaers, and P.K. Larsen, $J$. Appl. Phys., 78, 1926, (1995).

14. T. Noguchi, T. Hase, Y. Miyasaka, Jpn. J. Appl. Phys. Part 1, 9B, 4900, (1996)

15. K. Watanabe, M. Tanaka, N. Nagel, K. Katori, M. Sugiyama, H. Yamamoto, and H. Yagi, Integrated Ferroelectrics, 17, 451, (1997). 